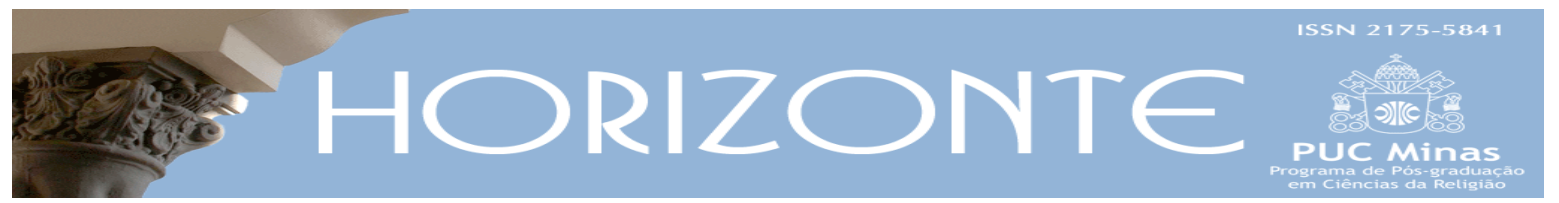

Temática Livre - Artigo original

(9) $(\Theta \Theta \Theta$

DOI - 10.5752/P.2175-5841.2015v13n37p504

\title{
A literatura europeia entre a fábula religiosa indiana e um Buda defraudado
}

\author{
The european literature between indian fable religious and defrauded \\ Buddha
}

\author{
Arilson Silva Oliveira*
}

\begin{abstract}
Resumo
Tem-se como objetivo apresentar que, em quase toda a Europa, nos períodos medieval e moderno, tornou-se recorrente as impressões imaginárias sobre as fábulas religiosas indianas e a vida de Buda, iniciadas quase dois mil anos antes na Grécia. As novelas medievais, por exemplo, com seus heroicos cavaleiros, assim como as fábulas modernas, possuem, todas, uma marca significativa, senão plágios, da literatura religiosa popular ou erudita indiana. Na verdade, aos nos basearmos metodologicamente na história das ideias, verificamos que foi a Índia (com seus imaginários mágicos) a fonte longínqua e literária do conto, apólogo, romance de cavalaria etc., que tanto encanto deram à época medieval europeia. Isto é confirmado por Theodor Benfey, um dos tradutores do Pañcatantra, nossa principal fábula indiana aqui exposta, ao pronunciar o dictum, em 1859, de que o grande número das fábulas mundiais, as quais foram produzidas no Ocidente, têm origem no mundo mágico da Índia; destas, um pequeno número já havia, inclusive, chegado à Europa como histórias orais, antes mesmo do século X.
\end{abstract}

Palavras-chave: Índia; literatura; Europa; plágio; Buda.

\begin{abstract}
The objective here is to present that, in most of Europe, in the medieval and modern periods, the imaginary impressions of Indian fables and the religious life of Buddha, which had already existed for almost two thousand years before in Greece, became recurring. All of the medieval novels, for example, with their heroic knights, as well as modern fables, have a significant mark, rather plagiarism, of popular or classical Indian literature. In fact, as we methodologically base ourselves in the history of ideas, we find that India was (with his magical imaginary) the faraway and literary source of the tales, the fables, the romances of chivalry etc., which gave much charm to medieval European times. This is confirmed by Theodor Benfey, one of the translators of the Pañcatantra, our main Indian fable exposed here, who pronounced the dictum, in 1859, that most of the world's fables, which were produced in the West, had originated in magical world of India, of which a small number had actually arrived in Europe as oral stories even before the tenth century.
\end{abstract}

Keywords: India; literature; Europe; plagiarism; Buddha.

\footnotetext{
Artigo recebido em 21 de setembro de 2014 e aprovado em 23 de março de 2015.

* Doutor em História Social e Professor Adjunto do Curso de Ciências Sociais da Universidade Federal de Campina Grande. País de origem: Brasil. E-mail: arilsonpaganus@yahoo.com.br.
} 


\section{Introdução}

Em quase toda a Europa, o que se aplica na historiografia positivista como final do período medieval europeu, tornou-se recorrente às impressões imaginárias sobre os escritos indianos, iniciadas quase dois mil anos antes na Grécia, mais especificamente com o relato do médico grego Ctésias de Cnidos para o rei persa Artaxerxes II, no século IV a.C. ${ }^{1}$

Todavia, o fato mais marcante durante o período medieval europeu, no tocante ao contato da Europa com a Índia, não foi a tentativa de aculturação cristã que se estendeu por vários lugares e tempos, mas o encontro positivo com a Índia através da divulgação da versão persa (ou do seu dialeto pahlavi ou pehlevi), e posteriormente árabe, da literatura sânscrita Pañcatantra, hoje mais fragmentada e conhecida como Kalila e Dimna. E o mais curioso e não menos surpreendente, de acordo com Arthur Macdonell, é que:

[...] a melhor e mais famosa das versões do Pañcatantra na Idade Média foi a germânica, de Anton von Pforr, ${ }^{2}$ intitulada Das Buch der Beispiele der alten Weisen, a qual apareceu em 1483, logo após a invenção da imprensa, e reimpressa posteriormente [em Estrasburgo]. Por um longo período ela contribuiu ao máximo com um conhecimento original por toda a Europa. [Desta forma,] ela não apenas influenciou a literatura germânica em muitos aspectos, mas foi também, ela mesma, traduzida para o dinamarquês, islandês e holandês [e iídiche, língua judaica]. Esta versão germânica estava quatro gerações distante dos árabes, desde o início da aventura ocidental do Pañcatantra (MACDONELL, 1994, p. 123).

Tal Pañcatantra, por uma via semelhante - versão em persa, depois em árabe, georgiano, grego e latim -, chegou também ao Portugal medieval,

\footnotetext{
${ }^{1} \mathrm{O}$ alemão e historiador da arte, Rudolf Wittkower (1901-1971), confirma que os mananciais que promoveram o bestiário mediévico, por exemplo, voltam-se ao passado helenístico, e aclara o andamento das imagens anômalas pelo meio artístico ocidental, partindo dos documentos helenísticos que abordam a geofísica mundial e as circunscrições do Oriente, assim como as empreitadas de Alexandre na Índia. Não obstante, Ctésias já havia registrado, logo após Heródoto descrever os afazeres ordinários indianos, um tratado que aborda excepcionalmente a Índia, aglomerando múltiplas ideias do orbe grego e persa e tracejando teratologias como os cinocéfalos (criaturas com cabeça de cachorro), os sciápodes, pessoas com abissais pés e que se movimentam com alta agilidade, entes sem cabeças e cujas faces se encontram no busto, além de unicórnios e outros. Tais relatos nutriram exaustivamente a fantasia do senso comum e dos doutos europeus (WITTKOWER, 1942).

${ }^{2}$ Donald Lach (1994, p. 347) observa que a versão germânica de Pforr também ficou conhecida como Seven Wise Masters [Os Sete Mestres Sábios]. Também há versões como The Seven Sages ou até The Seven Sages of Rome (CAMPBELL, 2009).
} 
juntamente com o Dhammapada (um dos mais famosos compêndios budistas), o Jātakamāla e o Lalitavistara - escritos biográficos e aforísticos sobre Buda.

Explicitamente, a dimensão ética e universal da vida de Buda inspirou o mundo oriental e parte do Oriente Médio de muitas maneiras, tendo atravessado transversalmente a história da humanidade em basicamente três fases: 1) o Dhammapada e o Jātakamāla seguiram as rotas do comércio oriental, percorridas pelos monges budistas no seu missionar pela Ásia até o Ocidente macedônio, grego e romano; 2) seguiu pelas traduções e adaptações árabes, espalhando-se pelo mundo árabe até a Europa; e, finalmente, 3) o missionar cristão acabaria por traduzir o mesmo Jātakamāla do árabe para o grego, quando João Damasceno (675-749) viveu na corte do califa Abdul-Malek, de Damasco, adquirindo uma versão pehlevi iraniana, 3 surgida na comunidade maniqueísta de Bagdá (BEINORIUS, 2005, p. 10).

A biografia de Buda viria, assim, a ser introduzida no universo cristão a partir do século VIII, com a designação latina Josaphat, que descende etimologicamente do grego Iosaph, do georgiano, Iodasaph, do árabe, Yudhasaf, do uigur (dialeto chinês adotado pelos budistas), Bodhasaf, do pāli (dialeto indiano), Bodhisatta, e este, por fim, do sânscrito Bodhisattva: "existência iluminada" ou "personificação da sabedoria". Foi assim que tal biografia cristianizada entrou no Martirológio como as vidas de Josafá (Josafate) e Barlaão, atestadas, aliás, pelo Martyrologium Romanum de 1583 (LACH, 1994, p. 102).

\section{Quando as ideias são aculturalmente transplantadas}

Tudo isso culmina, não por acaso do destino, na versão trecentista de Hilário da Covilhã (ou Lourinha): Vida do Honrado Infante Josaphate, Filho do Rey Avenir; uma versão cristianizada e plagiada da história de Buda e conservada em um manuscrito alcobacense; a ser publicada em 1963 por Margarida Corrêa de

\footnotetext{
${ }^{3}$ Dialeto do aramaico imperial persa e a língua oficial da corte dos arquemênidas (desde o século VII a.C.).
} 
Lacerda - sanscritista do então Instituto Superior de Estudos Ultramarinos, em Portugal. 4

No entanto, o Buda aqui sofrera uma translação em plagiário e uma notável metamorfose dogmática, vindo a transformar-se em um santo cristão, venerado tanto pela igreja grega como pela latina e comemorado no Martyrologium Romanum em 27 de novembro, e no calendário da Igreja Ortodoxa, em 26 de agosto (KACOBS, 1896, p. XVI-XVII). Mas não foi essa a única metamorfose que sofreu: na primeira versão persa - hoje perdida ou bem guardada no Vaticano virara aparentemente mestre maniqueísta, e, no Bilawharr wa Budhasaf árabe e persa moderno, o protótipo do Barlaão e Josafá (ou Josafate) cristão, senão um santo islâmico (o que seria uma heresia contra o seu profeta Muhammad) - ao menos um deísta fervoroso exemplar.

Mas o que nos diz a plagiada história de Josafá? O enredo básico da história apresenta um rei orgulhoso e poderoso, o qual persegue os ascetas religiosos que vivem em seu reino (obviamente cristãos) e os expulsa. Ele despreza o mundo, nega os ensinamentos monoteístas, ao mesmo tempo em que é um hedonista politeísta. Quando um dos filhos (Josafá ou Josafate) nasce, ele, como todo rei antigo, sente que sua linhagem real tornara-se segura, o que lhe proporciona pleno júbilo. No entanto, após previsões astrológicas em volta do nascimento da criança, surge a ideia de dois possíveis futuros para o menino: ele poderia se tornar um grande rei ou renunciar ao mundo, alcançando outro tipo de glória. Temendo que o destino de seu filho pudesse seguir o segundo curso, o rei o prende no palácio e o mantém afastado das imperfeições do mundo. Josafá, inevitavelmente, torna-se insatisfeito com a vida no palácio, e após muito insistir lhe é concedida a permissão para sair do mesmo - momento chave da trama -, ao que ele tem uma série de encontros perturbadores, basicamente as três primeiras do famoso quadro de sinais do Buda: doença, velhice e morte. Nesse momento, ele é visitado pelo asceta Barlaão, ou seja, o asceta do quarto sinal, o qual preenche quase todo o enredo como um

\footnotetext{
${ }^{4}$ Para pesquisa empírica, ver manuscrito no códice do mosteiro de Alcobaça, no 266, na Torre do Tombo, em Lisboa II.
} 
personagem que lhe dá instrução religiosa monoteísta e ascética. Josafá é aconselhado a renunciar o mundo para superar as misérias contempladas, que também o atingiram. Mas antes de sua renúncia, ele deve enfrentar muitos conflitos com o rei. No final, após um fervoroso diálogo com Barlaão, ele passa a viver asceticamente e morre na certeza de que será concedido a um lugar nos Céus. Com exceção do pregador cristão e do contexto monoteísta dogmático, observamos, aqui, a história de Buda quase em sua íntegra versão budista (LANG, 1966).

Com ricos detalhes a respeito, dirá Audrius Beinorius:

Desde 1000 d.C., uma versão da vida de Buda sob a forma de lenda de Barlaão e Josafá influenciou o ideal ascético cristão ocidental. O monge Euthymius, do Monte Atos, traduziu do seu georgiano nativo para o grego um conto de dois santos cristãos da Índia: um eremita cristão chamado Barlaão e um príncipe convertido, o Josafá. [Portanto,] Baseado na biografia sânscrita do altamente conhecido Buda: Budacarita, por Ashvaghosha (séculos II e III d.C.) - esta é a história de renúncia de Buda - provavelmente tenha fundado aqui o encontro entre o Oeste e o caminho através dos maniqueístas da Ásia Central, aprovando a história da renúncia de Buda para os seus próprios fins [cristãos]. Um texto em árabe dessa história, traduzido do dialeto pehlevi iraniano, apareceu no século VIII na comunidade maniqueísta de Bagdá. Assim, do sânscrito Bodhisattva tornou-se o uiguriano Bodhasaf, mais tarde, o árabe Yudhasaf, depois o georgiano Iodasaph, o grego Iosaph e, finalmente, o latim Josaphat. Este texto latino foi traduzido para muitas línguas ocidentais. Embora nunca tenham sido canonizados, no século XVI para Josafá e Barlaão foram, pela demanda popular, atribuídos um lugar no rol dos santos católicos romanos, sendo o seu dia 27 de novembro [ou 12 de novembro, como no Brasil]. Acreditava-se amplamente na Europa que a história de Barlaão e Josafá tivesse sido um relato da segunda conversão da Índia para o cristianismo, sendo a primeira promovida pelo apóstolo Tomé. Desta forma, a história [...] dos rudimentos da vida de Buda foi intencionalmente introduzida na Europa medieval, [e] encoberta com dogmas cristãos (BEINORIUS, 2005, p. 10-11).

Audrius Beinorius ainda observa que uma igreja cristã foi dedicada a Josafá em Palermo, na Sicília, enquanto a igreja de André d’Anvers, na França, guarda uma de suas enganadiças relíquias.5 Um dos primeiros europeus a noticiar as similitudes entre a história de Buda e a história de Barlaão e Josafá, junto à sua origem indiana, segundo Beinorius, foi o historiador português - que ajudou

\footnotetext{
${ }^{5}$ No Brasil, tem-se a igreja católica de Curitiba, dedicada a esse ícone budista que foi metamorfoseado em um fictício santo cristão, como tantos outros, no intuito aculturador desbravado ou, de fato, destruição das culturas não cristãs, como uma psicopatia incontrolável.
} 
Camões a voltar da Índia para Portugal e, assim, poder apresentar Os Lusíadas Diogo do Couto (1542-1616), em 1612. Mas a observação de Couto apontou apenas uma vida modelo de Josafá como sendo semelhante à de Buda. A união dos fatos, ou seja, a acusação de plágio e não de semelhança, veio à tona apenas com os franceses Eduoard Laboulaye (1811-1883) e Felix Liebrecht, em 1859 (Pitts, 1981, p. 3).

Philip Almond aponta que a história de Buda, juntamente com sua ideia ascética, foi, portanto, "uma força positiva à vida [sobrevivência e nova cosmovisão] do cristianismo". No entanto, a partir desse plágio dogmatizado e da tradição que se manifestou com Josafá e Barlaão, motivou-se o terror das perseguições antipagãs e heréticas na Europa - induzidas na obra -, assim como o monasticismo e o celibato acentuado, até então inexistentes no cristianismo, como métodos eficazes de salvação da alma (ALMOND, 1987, p. 406). Além disso, John Hirsh apontou acertadamente a atmosfera de "perseguição e intolerância" a partir da violação e descaracterização de tal apanágio budista (HIRSH, 1986, p. XXVI). Comparando-os, Monique Pitts nos diz: "para Buda a meta era atingir a iluminação perfeita [Buddhahood], [enquanto] para Josafá o ascetismo era a preparação para o mundo real, [ou para] aquele [mundo] que não pode ser visto” (PITTS, 1981, p. 10).

Em outras palavras, a igreja romana tomou a virtude búdica como modelo de santidade e, como tal, foi aceita e aprovada por Gregório III, Xisto V, Urbano VIII, Alexandre VII e Pio IX; além de introduzir fartos exemplos morais nas obras Gesta Romanorum, Vitae Patrum, Vitae Sanctorum e Disciplina Clericalis (IKEGAMI, 1999, p. 17).

Desse mesmo plágio cristão da vida de Buda, diz Theodor Garrat, Shakespeare adaptou vários apólogos budistas. Dois deles, aponta Garrat, são a "lenda dos três baús" (também encontrada no Decamerão de Boccaccio) e a "libra de carne", utilizada magistralmente por Shakespeare em The Merchant of Venice 
[O Mercador de Veneza], uma peça que relata os contrastes do espírito humano, escrita entre 1596-1598 e famosa por seus dois personagens principais: Antônio, o mercador, e Shylock, o agiota judeu. Uma de suas cenas, aliás, foi parodiada na peça O Auto da Compadecida do paraibano Ariano Suassuna - também transformada em filme.

Não obstante, suscitou o Pañcatantra grande número de versões na própria Índia, como a versão híndi de 1030 d.C., do árabe, filósofo e matemático Al-Bērūnī (973-1048), por um lado (MACDONELL, 1994, p. 122), e, por outro, a mais célebre, do autor Narayana, o Hitopadesha [Ensinamento Salutífero], uma das obras mais traduzidas do sânscrito para outras línguas, aquém, obviamente, dos épicos. ${ }^{6} \mathrm{E}$, apesar de ser um compêndio do Pañcatantra, há nele alguns contos que procedem de outras obras sânscritas. Dele surgiram diversas versões jainistas e em línguas vernáculas do Sul da Índia. No mais, observa-se que o Hitopadesha divide-se em quatro livros, com um total de 43 fábulas, das quais 25 são retiradas do Pañcatantra.

Sob o auxílio do filólogo alemão Theodor Benfey (1809-1881),7 a quem se deve a frase: "a Índia é a origem da civilização antiga, a qual se espalhou pela Europa junto com sua língua e histórias religiosas" (apud STACHE-ROSEN, 1990, p. 32-33) - permitimo-nos apresentar com maior precisão o descobrimento e o desenvolvimento da árvore genealógica destas fábulas. Para ele, não se há podido encontrar na Índia nenhum texto que corresponda exatamente ao Kalila e Dimna árabe, persa ou siríaco. No entanto, sua existência antes do século VI é certa, acrescenta Benfey; não só por este grupo de traduções, mas pela relação devedora ao célebre Pañcatantra, traduzido do sânscrito por Benfey (1859) em dois volumes, que, dos vários capítulos do Kalila, contém cinco, porém, muito mais desenvolvidos e amplificados interiormente: cada seção ou capítulo se compõe por

\footnotetext{
${ }^{6}$ Foi integralmente vertida ao português por Sebastião Rodolpho Dalgado (1855-1922), com o título Hitopadexa, editado pela Antiga Casa Bertrand em Lisboa, em 1897.

${ }^{7}$ Com uma introdução de 600 páginas, a qual é a mais completa já conhecida sobre o apólogo indiano. No juízo de Benfey, o Pañcatantra é obra de um budista que viveu no século III de nossa era. No entanto, hoje, consensualmente, segundo Moriz Winternitz (1985, p. 318), sabe-se que ele estava equivocado, pois o mesmo é de autoria brahmânica, com vários detalhes ortodoxos que o diferenciam do pensamento budista, e muito mais antiga à sua indicação temporal, existindo meras versões jainistas e budistas posteriores.
} 
um apólogo principal, no qual se intercalam outros vários, recitados pelos personagens da fábula e exornados com sentenças em verso.

Todavia, a maior parte destes apólogos havia servido como exemplos aos pensadores budistas, que se dirigiam à massa da população interessada recitando-a em jatakas (parábolas biográficas). Devemos observar que o Pañcatantra foi redigido em pāli, dialeto próximo ao sânscrito e língua dos cânones da escola budista Theravada, desenvolvida amplamente no Ceilão, de onde, a partir do século XI d.C, devido à "expulsão" política do budismo da Índia pelos islâmicos e filosófica por Shankara, 8 também conquistou o Camboja, a Birmânia, o Sião e o Laos. As fábulas budistas aparecem unidas, por exemplo, ao Khuddaka Nikaya, em sua quinta e última seção do Sutta-pitaka ou segunda parte do Tripitaka, as três coleções canônicas budistas proferidas por Buda e seus discípulos mais próximos, durante os quarenta e cinco anos da sua atividade como iluminado. Tal fato compreende todo o conhecimento transmitido por Buda em três ocasiões e lugares distintos. Sendo elas, as fábulas, ilustradas em 547 prosas, das quais algumas têm paralelos nos épicos Ramayana e Mahabharata e nos devocionais Puranas, podese concluir que todas possuem origem brahmânica. Coincidentemente ou não, algumas dessas fábulas budistas apareceram logo após o segundo concílio budista em Vaishali (390 a.C.). Tais fábulas são conhecidas como jatakas ou "nascimentos", por serem prováveis narrações de vidas anteriores do próprio Buda (AKIRA, 1993, p. 79, 160, 268).

Isso nos leva a presumir que a maior parte destas parábolas, fábulas e provérbios é anterior ou contemporânea ao nascimento do budismo, notadamente, com sentidos diversos do hinduísmo, já que, para os seus ouvintes, os budistas as empregavam com uma nova roupagem moral (JACOBS, 1888).

Conclui-se, então, que as fábulas indianas são milenares, ora nascentes da natural tendência da mente humana de tomar a metáfora pela realidade e as figuras

\footnotetext{
${ }^{8}$ Filósofo indiano Shankara (VIII-IX d.C.), um dos pensadores de maior influência dentro da Índia (e até fora dela) no que diz respeito à discussão do Yoga ou mesmo às diversas escolas de pensamento indianas que migraram para o Ocidente.
} 
de linguagem por histórias e contos, que é o ponto de vista filológico indicado por Ernst Kuhn (1846-1920) e tão vulgarizado e deturpado pelo desencantado Max Müller; ora pertencentes a uma remota e misteriosa fonte em vagas memórias da ancestral comunidade dos pensadores ăryas, como parece indicar a presença de algumas delas em ramos descendentes e familiares; especialmente nas tradições germânicas e bem marcantes em seus famosos trabalhos literários.

Inicialmente, temos um dos marcos irreverentes da literatura europeia, Tristão e Isolda, do século XII, que Theodor Garratt (2007, p. 24), Moriz Winternitz (1985, p. 382), Arthur Macdonell (1994, p. 128) e Donald Lach (1994, p. 102) relacionam, a partir da versão de Gottfried von Strasbourg, 9 com a Índia via Pérsia. Afirmam tais autores que Tristão e Isolda se conecta com a obra Tutināmeh persa, no sentido de uma real "ordem fraudulenta" (Garratt e Macdonell) ou falsificação (Winternitz), e que, por sua vez, é uma tradução do Shukasaptati indiano, uma versão do Pañcatantra. Em outras palavras, Tristão e Isolda, na realidade, nada mais é do que uma versão copiada do Pañcatantra, via tradução persa.

Uma conexão visível também se apresenta entre Kalila e o consagrado Beowulf, provavelmente o mais antigo texto épico - entre os séculos VIII e XI, com referências de heróis nórdicos dos séculos V e VI (TOLKIEN, 1958, p. 127; HIEATT, 1983, p. xi-xiii.) -, sobrevivente dos ataques e alterações cristãs da literatura anglosaxônica - essencialmente, uma história germânica -,,10 como nos dirá George W. Dasent em Popular Tales from Norse Mythology. Dasent (1859, p. 47-48) apontará sua conexão com a Índia:

Assim, encontramos nele [no Pañcatantra] os originais ou os paralelos com o Grendel no Beowulf, de Rumpelstiltskin, da recuperação da noiva pelo anel derrubado na taça, conforme relatado no Soria Moria Castle, e outros contos; o do "carneiro dos desejos", que na estória Indiana se torna a "vaca dos desejos", e, portanto, nos lembra do touro em um dos Norse

\footnotetext{
${ }^{9}$ No processo de reconstituição dos poemas medievais, Joseph Bédier reuniu os fragmentos escritos por Béroul, Thomas, Eilhart von Oberg, Gottfried von Strasbourg e outros, registrados em sua maioria entre os séculos XII e XIII, na França e na Germânia. Mais uma vez a Germânia em cena e em torno de uma obra com influência indiana (BÉDIER, 1981).

${ }^{10}$ Como elucida Peter Baker: "[...] temas no Beowulf e em trabalhos relacionados e anteriores a ele, pensando especificamente na Germânia, podem ser encontrados primeiramente na tradição épica indo-europeia" (BAKER, 1998, p. 284).
} 
Tales, de cuja orelha sai o "manto dos desejos"; da criança afortunada que encontra uma bolsa de ouro embaixo de seu travesseiro todas as manhãs; e do tecido vermelho costurado por sobre o amante, como para com Siedfried no Nibelungen. A estratégia de Upakosa, a esposa fiel, nos remete imediatamente ao The Mastermaid, e todas as estórias de Saktideva e da Cidade Dourada, e as de Viduschaka, filha do Rei Adityasena, são de mesma base e em muitos de seus incidentes iguais a East o' the Sun, and West o' the Moon, The Three Princesses of Whiteland e Soria Moria Castle. ${ }^{11}$

Michael Stitt vai mais além, afirmando que não é mera coincidência a relação e o paralelismo dos mitos de dragões presentes no medievo europeu como bem apresentado em Beowulf -, com a história védica ( $R g$ Veda, I.32.5) do deus Indra matando o dragão Vrtra: "Indra com o seu grande e mortal trovão partiu em pedaços Vrtra, o mais terrível dos vrtras [serpentes ou dragões]. Assim como troncos de árvores, quando o machado cai sobre eles, da mesma forma, caído ao chão jaz prostrado o dragão". ${ }^{2}$ Dirá Stitt (1992, p. 31):

Esta passagem, quando somada com as diversas outras referências fragmentárias da batalha de Indra com Vrtra, representa a tradição que é paralela a vários aspectos da nossa tradição medieval. O perpetrador da vilania é Vrtra, também conhecido como Ahi, ou "serpente", um ser demoníaco compreendido como um dragão. Vrtra aprisionou, em sua caverna, as águas que dão a vida, que são apresentadas como seres femininos na forma de vacas. Indra combate o dragão tomando o Soma, um líquido [ritualmente] dotado de poder. Após Vrtra ser exterminado, Indra mata [também] sua mãe. Nesse momento, o corpo desmembrado de Vrtra é levado para fora da caverna pelas correntezas [da água] liberadas.

Complementará Peter Baker (1998, p. 284) que "a Fêmea Formidável", dragão mãe de Vrtra, nos Vedas, antecipa o mais temível humanoide de Grendel que, por sua vez, é finalmente substituído por uma senhora de idade instável no romance de Fulk, e as águas da vida (entidades femininas) aprisionadas por uma donzela raptada.

De acordo com Geoffrey Garratt (1950, p. 48), um século após a versão germânica de 1481, a fábula indiana foi traduzida para o italiano, e desta para o

\footnotetext{
${ }^{11}$ Também ver evidências em Baker (2000, p. 59).

${ }^{12}$ Ver também Rg Veda IV.17.7 e todos os versos anteriores e subsequentes ao referido: I.32.1-15.
} 
inglês por Thomas North, o tradutor de Plutarco, sendo tal tradução inglesa certamente conhecida por Shakespeare.

Surgem também conexões semelhantes com as obras do literato realista e poeta italiano Boccaccio (1313-1375), em sua estrutura narrativa do Decamerão, com The Canterbury Tales, do pai da literatura inglesa Geoffrey Chaucer (13431400) ${ }^{13}$ e com o consagrado pai da fábula moderna, o francês La Fontaine (16211695). Além e após La Fontaine, outros fabulistas importantes encheram-se de deleites com os escritos de origem indiana, tais como o condecorado (pela Academia Francesa) Jean-Pierre Claris de Florian (1755-1794), o poeta e dramaturgo inglês John Gay (1685-1732) e os espanhóis Félix María Samaniego (1745-1801) e Tomás de Iriarte (1750-1791), os quais consagraram definitivamente o gênero fabulista na Europa; além das reconhecidas fábulas germânicas de Gotthold Lessing, no final do XVIII, e dos irmãos Grimm (Jacob e Wilhelm), no início do XIX (Macdonell, 1994, p. 124).

Mas as influências não param por aí, pois, de acordo com Duncan MacDonald (1924, p. 371) e Nabia Abbott (1949), Alf Lailah wa-Lailah ou As Mile Uma Noites possuem claras e profundas marcas indianas em todo o seu escopo e arranjo, bem como as histórias árabes de Sindibād al-Baḥri ou Sindba, o Marinheiro. No caso de Sindba, uma palavra de origem persa, é mais conhecido na Europa como Seven Sages of Rome. O autor da obra, um persa sassânida, segundo Paul Starkey e Meisami Scott (1998, p. 24), foi marcado pelas narrativas indianas e possivelmente em versões persas, o que justifica sua influência visível. Já para Joseph Jacobs, o mesmo teria sido influenciado pelas famosas fábulas gregas de Esopo; possuindo estas uma estreita similaridade com as fábulas jatakas budistas - algo que ele discute na sua introdução de Aesop, de William Caxton. Opinião também defendida, mas sob a alegação de uma tradução direta do persa por parte de Esopo, por Gautamavajra Vajrācārya (2002, p. 59) e Radhakamal Mukerjee (1959, p. 139).

\footnotetext{
${ }^{13}$ Sobre a conexão de Boccaccio e Chaucer com as fábulas indianas, ver: Ganin (2000, p. 128-147).
} 
Prosseguindo com as relações, observa-se que dois dos contos presentes no Hitopadesha possuem analogias com os relatos VII, VIII e IX da Disciplina Clericalis, ${ }^{14}$ do tradutor, astrônomo e médico da corte de Afonso VI e rei de Castela e de Leão, Petrus Alphonsi, mais conhecido como Pedro Alfonso (1062-1140), que os tomou seguramente de alguma versão árabe (PALENCIA, 1928, p. 309-310). Michael Barry (1992, p. 211) chama a atenção para a origem indiana do conto de Alfonso:

[...] é no domínio mais humilde e familiar do conto, do fabliau, que a marca árabe foi mais evidente. Exemplo primordial: a técnica narrativa de origem hindu, que consiste em encaixar uma série de contos uns nos outros, com um conto-prólogo para servir de moldura. Passando pela Pérsia e pelo Oriente Próximo árabe, essa técnica literária chegou, na Idade Média [europeia], até a Espanha. As Mil e Uma Noites constituem apenas uma amostra popular desse gênero de literatura. Um exemplo mais estimado pelos próprios letrados muçulmanos é a coleção de fabliaux, tendo como personagens: animais de Kalila e Dimna, de longínqua origem hindu, traduzida para o árabe culto, no século VII, pelo iraniano Ibn al-Muqaffa, através de uma tradução hebraica na Espanha, antes de influenciar La Fontaine.

Aqui, mais uma vez, a marca da literatura indiana adentra o cenário de $A s$ Mil e Uma Noites.

Confirma-nos a sanscritista Valíria Mello Vargas, em sua tradução do Pañcatantra (2004), que o mais afamado fabulista francês do século XVII, La Fontaine, em suas Fabules, prefácio do sétimo livro, menciona Pilpay; que, na verdade, é uma corruptela do sânscrito vidya-pati, "senhor da sabedoria”, epíteto de Vishnusharma, como o já referido autor da obra. Mello Vargas infere que há muitas razões suficientes para considerarmos que La Fontaine possui marcas ou se baseou nas versões (de Kalila e Dimna) francesas Livre des Lumières de David Sahid, e na versão latina de Pierre Poussines (1609-1686), Specimen sapientiae

\footnotetext{
${ }^{14}$ De acordo com John Tolan, o tratado Disciplina clericalis é uma das antologias de relatos moralizantes medievais mais veneráveis da Europa cristianizada. Tais narrações voltam-se para distrair, doutrinar e nortear os passos dos homens. Abarcando adágios, versos, fábulas e anedotas tomadas das tradições árabes, judias, gregas e principalmente indianas. Famoso no medievo europeu e traduzido de sua versão original em latim ao francês, basco, italiano, castelhano e inglês, sobrevive hoje em 76 manuscritos latinos, nos quais constam 34 relatos estruturados em diálogos entre mestres e discípulos e cujo principal objetivo é conduzir mandamentos utilitários. Acrescentará John Tolan que Pedro Alfonso se utilizou fartamente das fontes árabes e indianas (TOLAN, 1993, p. 132-158).
} 
Indorum Veterum, para compor muitas de suas fábulas; as mesmas fábulas que contagiaram alguns dos homens da razão na modernidade europeia.

Porém, a saga de tal literatura fora da Índia começou com o rei persa Chosroes Anusharvan (531-579 d.C.), que enviou à Índia um de seus 25 médicos, Barzuyeh, em missão ao encontro de ervas medicinais que ressuscitavam mortos e propiciavam imortalidade. Como a Índia sempre manifestou e nos manifesta prodígios da razão, além das aparências, àqueles que a procuram, Barzuyeh teve uma surpresa além do esperado.

Segundo o Shahnameh (1985, p. 330-334), "Épicos dos Reis”, considerado a certidão identitária do povo persa, 15 Barzuyeh obteve permissão para ir à Índia em busca das ervas mágicas. Uma vez ali, encontrou tais ervas, mas as mesmas não possuíam efeitos sem a manipulação e o conhecimento adequado de suas propriedades; o que obviamente resultou em fracassos aparentes para Barzuyeh. Ansioso e com medo da reação do rei pela até então missão infrutífera, passou a consultar os brahmanas sobre a manipulação da mesma. Todos inclinados, logicamente, a não revelar nenhuma literatura canônica ao médico mleccha. Mas tratando-o como uma criança sem linhagem, conhecimento e ética védicas de fato, que de alguma forma poderia ser ajudada, ${ }^{16}$ disseram ao mesmo: "Há um antigo

\footnotetext{
${ }^{15}$ Trata-se de uma grande obra poética escrita no século X d.C., pelo escritor iraniano Hakīm Abu'l-Qāsim Firdawsī Tūsī ou simplesmente Ferdowsi (935-1020), a qual narra a história do Irã e do zoroastrismo, desde a manifestação do mundo até as conquistas islâmicas nos seus primórdios. Foi elaborado durante 30 anos, resultando em 62 histórias, 990 capítulos e 56.700 dísticos. Não obstante, após as empreitadas militares islâmicas, a língua pahlavi esvaeceu dos documentos, agora substituída pelo árabe. Apenas no século IX a língua ressurge, agora semelhante ao persa moderno e fruto da mutação falada do pahlavi e do agrupamento de palavras árabes. A obra serviu e serve de objeto de pesquisa para inúmeros historiadores e inspiração para inúmeros poetas do mundo, além de hoje está selada como memória registrada do mundo pela UNESCO (ANVARI, 2004).

${ }^{16}$ A moral da obra não é certamente muito elevada em relação aos padrões védicos, ou seja, sem a tragédia e o realismo do estilo indiano. Na fábula, há predominado desde suas remotas origens, notadamente indiana, certo sentido utilitário, o que nos leva a aceitar que "um rei que tomara por modelo o rei dos animais tal como está representado nestes contos, careceria de energia e de valor, cederia ao primeiro movimento de cólera, violaria sem escrúpulos a fé jurada e abandonaria pelo menor capricho o serviço a um amigo e a fidelidade de uma esposa" (DERENBOURG, 1881, p. 208). Ou seja, seria um rei não brahmânico, sem pura paixão, senso de proporção e determinação política vocacional (WEBER, 1972, p. 106); enfim, sem dever ou dharma de um verdadeiro guerreiro ou kshatriya indiano. $\mathrm{O}$ que nos leva a concluir que as ideias presentes nessa fábula, em sua versão persa ou árabe, estão muito longe do pensar indiano, apesar de conter originalmente um apelo e um caráter popular de fonte brahmânica e versões budistas, suprimida por Barzuyeh, o qual a transformou em uma teologia simplicíssima. E pode se dizer até que a reduziu a um elementar deísmo, sem profundidades de nenhum gênero, salvo para resolver a contradição entre a presença divina e o livre arbítrio humano. Só assim podemos pensar e explicar como estes apólogos hão podido acomodar-se com tanta facilidade a civilizações tão diversas e hão tido séquito entre homens de opostas crenças. Desta forma, como expressão do vulgo, a fábula representa uma primeira fase da sabedoria técnica, prática, massificada e com deísmo sentimentalista; portanto, direcionada muito mais por sua doutrina do que por seus exemplos, com seu lado pitoresco e formal. Por tudo isso, a indicação de tal obra para um mleccha persa induz-nos a pensar sobre a real intenção dos brahmanas diante de Barzuyeh: dar o máximo que um bárbaro pode compreender e aplicar, sem filosofia sistemática ou política vocacional.
} 
brahmana que nos supera em idade, ciência e sabedoria, ele poderá lhe ajudar". Quando Barzuyeh encontrou-se com o famoso brahmana, lhe explicou toda a aventura em busca da erva mágica. Ao concluir sua justificativa diante do brahmana, este lhe replicou:

[...] eu também tive vários fracassos ao buscar com impaciência e esperança, mas quando nada demonstrava alguma luz, forçava-me a olhar com uma interpretação diferente. Pois, na realidade, a erva é o científico e a ciência é a montanha eternamente fora do alcance da multidão. $\mathrm{O}$ cadáver é o sem conhecimento que através do conhecimento se revive. Desta forma, te informo que na tesouraria de nosso rei há um livro que os bem qualificados [brahmanas] chamam de Kalila, e quando nos encontramos cansados da ignorância, a erva é Kalila e o conhecimento a sua montanha. Se buscares este livro dentre os tesouros do rei, o encontrarás. Ele será o guia para o teu conhecimento. (SHAHNAMEH, 1985, p. 334).

Consequentemente, ao regressar da Índia, Barzuyeh apresentou uma coleção de contos, apólogos morais e populares da Índia, traduzidos por ele para o pahlavi, ao invés das ervas mágicas e terapêuticas. O original seria uma espécie de antropomorfia em sânscrito com a figuração de dois chacais, Karațaca [uivo espantoso] e Damanaka [vencedor], dialogando proeminentemente entre eles e na forma de uma narrativa moral. O médico Barzuyeh intitulou sua antologia Kalila and Damnag, nomes dos chacais em pahlavi. Duzentos anos mais tarde, século VIII, um persa zoroastrista que se convertera ao islamismo, Abd-Allah Ibn alMuqaffa, ministro do califa abássida de Bagdá, Almanzor, a verteu para o árabe, a partir da versão de Barzuyeh, dizendo-a Kalilah wa Dimnah (IRWIN, 2006). ${ }^{17}$ Este volume teve a mais extraordinária repercussão que é possível supor para uma literatura em termos mundiais. Lembra-nos Mello Vargas que al-Muqaffa "revela no prefácio à obra, que a coletânea árabe consiste em uma reelaboração da versão em pehlevi”, do século VI, “e que esta, por sua vez, seria uma compilação de fábulas sânscritas" (PAÑCATANTRA, 2004, p. 10). Traduzido, imitado, plagiado e comentado, deu tal fábula nascimento a centenas de histórias, lendas e contos dispersos por toda a parte, da Europa à Ásia.

\footnotetext{
${ }^{17}$ Aqui há 14 comentários sobre essa versão árabe.
} 
Sobre o texto de Ibn al-Muqaffa, fizeram-se mais tarde adaptações em verso, uma nova tradução siríaca, versões em prosa em persa moderno, em turco e em mongol, e, ainda, através de um manuscrito egípcio levado para a Abissínia, uma versão etíope - hoje também perdida ou ocultada. Uma das três ou quatro recensões turcas existentes - a de Ali Chelebi Ibn Salih, em prosa otomana no início do século XVI, feita sobre uma versão persa e intitulada Humayun-name [livro imperial] - veio no século XVII a ser traduzida em castelhano e, em seguida, em francês.

Tal variante de Ibn al-Muqaffa foi transladada em algumas ocasiões para a língua dos hebreus: inicialmente, no século XII, pelo rabino Joel; posteriormente, no século seguinte, por Jacob Eleazer (em conversação poética e próxima da versão original). Em meados do século XIII, a pedido de Afonso X, foi transladada para o castelhano, a partir de uma resenha islâmica muito conexa à que empregara o rabino - sobrevivente via cópias do mosteiro Escurial de Madri. Se servindo posteriormente desse texto D. João Manuel, neto de Fernando III de Leão e Castela, para elaboração do seu El Conde Lucanor, ${ }^{18}$ o qual existia na biblioteca do rei Duarte, uma das vias pelas quais os fabulários indianos aproximaram-se do primeiro grande dramaturgo e pai do teatro português, Gil Vicente (1465-1536).

Vicente chegou a elaborar a peça Auto da Índia, um sucesso na época, apesar de ser contrária, com visão mordaz, à invasão portuguesa na Índia; tendo sua primeira representação em 1509, diante da rainha portuguesa D. Leonor de Avis.

Todavia, afirmar que todas estas traduções foram feitas com o amplo rigor de outrora seria escuso, já que dificilmente tais versões, sem a austeridade e motivação brahmânica à preservação, estariam sujeitas a amputações, introduções de dogmas particulares, dentre outras adições, modificações e acréscimos ao texto original; alguns destes, retirados de outras fontes. A obra de Barzuyeh, por exemplo, contém uma espécie de apêndice, afirmando que as três primeiras

\footnotetext{
${ }^{18}$ Em castelhano antigo: Libro de los enxiemplos del Conde Lucanor et de Patronio.
} 
narrativas são retiradas do livro XII do épico Mahabharata (Shanti-parva) e as cinco seguintes de uma história do "rei dos ratos e seus ministros" - do qual o original indiano se não se tem acesso facilmente.

Já no século XIII, o dominicano francês Jourdain de Severac (ou Jordão de Catalão), após ter sido nomeado bispo pelo papa João XXII, foi enviado à Índia para tentar fazer algum contato (invadir) e descobrir (maquinar) melhores maneiras de aculturar (destruir) os ameaçadores pagãos (TOMAZ, 1991, p. 127). Tal bispo, em 1328, elaborou a Mirabilia Descripta ou uma “magnífica descrição" do Oriente, incluindo vários capítulos sobre a Índia. Mas tal descrição, longe de ser uma "magnífica descrição", na verdade, descreve apenas a natureza (os frutos locais, ${ }^{19}$ espécies de animais, montanhas), e a "heresia” dos pagãos com seus rituais estranhos e (em contraste com) os mártires cristãos. Uma exemplar manifestação, isto sim, de estranhamento, de repúdio e de ênfase ao exotismo.

A tradução encomendada por Afonso X, em 1251, fora brindada à rainha Joana de França, esposa de Filipe, o Belo, que, por sua vez, encomendou a Ramon de Bèziers a tradução para o latim. Posteriormente, João de Cápua, sob o patrocínio do cardeal Matteo Orsini, traduziu Kalila e Dimna do hebraico também para o latim entre 1263 e 1278, nomeando-o Directorium humanae vitae (Balaguer, 1985, p. 320). Sob tão alto patrocínio, o Directorium, cujo autor não passava, segundo Derenbourg (1881), de mediano, hebraizante e fraco helenista, penetrou imediatamente no cenário teológico cristão.

Por conseguinte, o escritor e filósofo catalão Raimundo Lúlio (ou Ramon Llull, 1232-1315), falante e conhecedor da cultura árabe e que escreveu a primeira literatura catalã e a primeira novela europeia, Blanquema, em 1283 (BLACKMORE, 1999, p. 170), teve contato com uma destas versões de Kalila $e$ Dimna; possivelmente a latina de João de Cápua, observa Balaguer (1985, p. 320).

\footnotetext{
${ }^{19}$ Muitos facilmente encontramos no Brasil, todos de origem indiana e trazidos pelos portugueses, tais como a manga, espécies de arroz, o sapoti, a jaca, o coco, o jambo ("maçã rosa" em sânscrito), a cana-de-açúcar, a tamarindo, algumas espécies de pimenta, o cravo e o gado.
} 
Llull oportunamente a transformou em pretexto para doutrinar moralmente a monarquia de seu período, servindo de catequização aos monarcas, com a elaboração, por exemplo, do Livro das Bestas (LÚLIO, 1990), dedicado ao rei Filipe IV da França. Diríamos que se configura como um plágio bem acurado e de sucesso, já que vários Exempla do bestiário medieval de Kalila e Dimna reaparecem narrativamente no Livro das Bestas: o papagaio, o símio, o leão e a lebre, o vaga-lume etc.

Uma vez que os exemplos originais de Llull sejam a eleição do rei e do bispo e o ermitão e o rei, por exemplo, nota-se que são modelos da adulteração dos habitus. Em contrapartida, os contos indianos, que foram plagiados no Livro das Bestas, têm uma modulagem muito mais esquemática (BALAGUER, 1985, p. 321); no entanto, todos os protótipos relatados no Livro das Bestas possuem a mesma acepção moralizante, qual seja: a iniquidade da raposa (corrupção via poder) convenha de modelo para que os homens da realeza se mantenham vigilantes contra todos, inclusive seus próximos.

Da versão latina Directorium humanae vitae procedeu-se uma tradução germânica (1481) - um dos primeiros livros impressos no mundo, segundo Theodor Garratt (1950, p. 48) - dedicada ao cardeal Mateo Orsini e intitulada Beyspiele der Weisen von geschlecht zu geschlecht [Exemplos dos Sábios de Geração a Geração], que se há atribuído ao duque de Würtemberg, Eberhard I (1445-1496); provavelmente o seu patrocinador. Há, enfim, outra versão germânica, intitulada Ueber Inhalt und Vortrag, Entstehung und Schicksale des Koniglichen Buchs [Sobre Conteúdos, Narrativas, Origem e Aventuras do Livro dos Reis], publicada em Berlim, em 1811, e doada pelo embaixador russo (Heinrich Friedrich von Diez) ao líder alemão (THACKER, 1823, p. 505). Versões espanhola e francesa e duas outras italianas surgiram ainda no século XVI. 


\section{Conclusão}

Assim sendo, as novelas medievais, com seus heroicos cavaleiros etc., bem como as fábulas modernas, possuem, todas, sejam marcas profundas, sejam plágios ou uma inspiração catártica da literatura popular indiana e das histórias do príncipe indiano que posteriormente viria a se tornar o Buda. Na verdade, foi a Índia a fonte longínqua e literária do conto, apólogo, romance de cavalaria e até mesmo de alguns "santos" cristãos, dentre outros, que tanto encanto deram à época medieval. E, de quando em quando, ainda aparecem outros ocidentais que não podem resistir ao seu fascínio aliciante.

Isto é confirmado por Theodor Benfey, como observamos anteriormente, um dos tradutores do Pañcatantra, ao pronunciar o dictum, em 1859, de que o grande número das fábulas mundiais, as quais foram produzidas no Ocidente, têm origem na Índia; destas, um pequeno número já havia chegado à Europa como histórias orais, antes mesmo do século X (LACH, 1994, p. 100). O filósofo e historiador britânico James Mackintosh (1765-1832),20 o folclorista francês Emmanuel Cosquin (1912) e o historiador e crítico literário espanhol Menéndez Pelayo (1905) também confirmam a Índia como uma região de origem, centro e disseminação da fábula ao mundo. Pelayo, no mais, chega a relatar que Kalila e Dimna foi recitada por Ricardo, Coração de Leão, em 1195, ao censurar os príncipes cristãos que não queriam se armar para a cruzada.

\footnotetext{
${ }^{20}$ Afirmará sem reservas Mackintosh: “Todos os pontos da história voltam-se para a Índia como a mãe da ciência e da arte. Este país foi antigamente tão famoso por seu conhecimento e sabedoria que os filósofos da Grécia não tardaram a viajar para lá para aprimoraremse" (apud Danino, 1996, p. 18).
} 


\section{REFERÊNCIAS}

ABBOTT, Nabia. A ninth century fragment of the "Thousand and One Nights": new light on the early history of the arabian nights. Journal of Near Eastern Studies, [s.l.], v. 8, n. 3, p. 157-178, jul. 1949.

AKIRA, Hirakawa. History of Indian Buddhism: from Śākyamuni to early Mahāyāna. New Delhi: Motilal Banarsidass, 1993.

ALMOND, Philip. The Buddha of Christendom: a review of the legend of Barlaam and Josaphat. Religious Studies, [s.l.], v. 23, n. 3, p. 391-406, set. 1987.

ANVARI, Hassan. Ancient Iran's geographical position in Shah-Nameh. Iran: Chamber Society, 2004.

BAKER, Peter Stuart. Words and works: studies in medieval English language and literature in honor of Fred C. Robinson. Toronto: University of Toronto Press, 1998.

BAKER, Peter Stuart. The Beowulf reader. London: Routledge, 2000.

BALAGUER, Jordi Rubió. Ramon Llull i el Lullisme. Barcelona: Abadia de Montserrat, 1985 .

BARRY, Michael. A influência dos contos árabes. In: CARDAILLAC, Louis. Toledo, Séculos XII-XIII. Muçulmanos, Cristãos e Judeus: o saber e a tolerância. Rio de Janeiro: Jorge Zahar Editor, 1992.

BÉDIER, Joseph. Le Roman de Tristan et Iseut. Paris: Union Générale d'Editions, 1981.

BEINORIUS, Audrius. Buddhism in the Early European Imagination: a Historical Perspective. Acta Orientalia Vilnensia, [s.l.], v. 6, n. 2, p. 7-22, 2005.

BENFEY, Theodor. Pantschatantra, fünt Bücher indischer Fabeln Märchen und Erzählungen aus dem Sanskrit übersetz. Leipzig: Brockhaus, 1859. v. 2.

BLACKMORE, Josiah; HUTCHESON, Gregory. Queer Iberia: sexualities, cultures, and crossings from the middle ages to the renaissance. Durham: Duke University Press, 1999.

CAMPBELL, Killis. A study of the romance of the Seven Sages with special reference to the middle english versions. Charleston: BiblioBazaar/ LLC, 2009.

COSQUIN, Emmanuel. Les Mongols et leur Prétendu Rôle dans la Transmission des Contes Indiens vers L’Occident Européen. Revue des Traditions Populaires, [s.l.], v. 27, n. 9, p. 337-373, set. 1912.

DANINO, Michel. The invasion that never was: song of humanity. Delhi: Mother's Institute of Research \& Mira Aditi, 1996. 
DASENT, George Webbe. Popular tales from Norse Mythology. Edinburgh:

Edmonston and Douglas, 1859.

DERENBOURG, Joseph. Deux Versions Hébraïques du Livre de Kalîâ et Dimnâh. Paris: F. Vieweg, 1881.

GANIN, John. Chaucer, Boccaccio, Confession, and Subjectivity. In: KOFF, Leonard Michael; SCHILDGEN, Brenda Deen (Org.). The Decameron and the Canterbury

Tales: new essays on an old question. London: Associated University Press, 2000. p. 128147.

GARRATT, Geoffrey Theodor. El legado de la India. Madrid: Pegaso, 1950.

GARRATT, Geoffrey Theodor. The legacy of India. Warwickshire: Read Books, 2007.

HIEATT, A. Kent. Beowulf and other old english poems. New York: Bantam Books, 1983 .

HIRSH, John (Ed.) Barlam and Iosaphat: a middle english life of Buddha. London: Oxford University Press, 1986.

IKEGAMI, Keiko. Barlaam and Josaphat. New York: AMS Press, 1999.

IRWIN, Robert (Ed.). The penguin anthology of classical arabic literature.

London: Penquin Books, 2006.

JACOBS, Joseph. Introduction. In: The earliest english version of the Fables of Bidpai. London: D. Nutt, 1888. p. 10-43.

JACOBS, Joseph. Barlaam and Josaphat: english lives of Buddha. London: David Nutt, 1896.

LACH, Donald F. Asia in the making of Europe: the literary arts. Chicago: University of Chicago Press, 1994.

LANG, David Marshall (Trad.). The Balavariani (Barlaam and Josaphat): a tale from the Christian East translated from the old georgian. Berkeley: University of California Press, 1966.

LÚLIO, Raimundo. Livro das bestas. São Paulo: Edições Loyola, 1990.

MACDONALD, Duncan B. The Early History of the Arabian Nights. Journal of the Royal Asiatic Society, [s.l.], p. 353-397, 1924.

MACDONELL, Arthur. India's past: a survey of her literatures, religions, languages and antiquities. New Delhi: Asian Educational Services, 1994. 
MEISAMI, Julie Scott \& STARKEY, Paul. Encyclopedia of arabic literature. London: Taylor \& Francis, 1998.

MUKERJEE, Radhakamal. The culture and art of India. New York: Praeger, 1959.

PAÑCATANTRA. Tradução Maria Valíria Vargas (et.al). Pañcatantra: fábulas indianas, livro I. São Paulo: Iluminuras, 2004.

PALENCIA, Angel Gonzalez. História de la literatura Arábigo-Española. Barcelona: Editorial Labor S.A., 1928.

PELAYO, Marcelino Menéndez. Origenes de la novela. Madrid: CSIC, 1905.

PITTS, Monique. Barlaam and Josaphat: a legend for all seasons. Journal of South Asian Literature, [s.l.], XVI, p. 1-16, 1981.

RG VEDA. By Ralph T. H. Griffith. The Hymns of the Rgveda. Delhi: Motilal Banarsidass, 1976.

SHAHNAMEH. The Shāh Nãma, the Epic of the Kings. Translated by Reuben Levy and revised by Amin Banani. London: Routledge \& Keegan Paul, 1985.

STACHE-ROSEN, Valentine. German indologists: biographies of scholars in Indian studies writing in Germany. New Delhi: Max Mueller Bhavan, 1990.

STITT, Michael. Beowulf and the bear's son: epic, saga, and fairytale in northern germanic tradition. New York: Garland Publishing, 1992.

THACKER, W. (Ed.). The Oriental Magazine and Calcutta Review. Calcutta: Andrew's Library, 1823. v. 1.

TOLAN, John. Petrus Alfonsí and his medieval readers. Gainesville: University Press of Florida, 1993.

TOLKIEN, J.R. Beowulf: the monsters and the critics. London: Oxford University Press, 1958.

TOMAZ, Luis Felipe. A carta que mandaram os padres da Índia, da China e da Magna China. Revista da Universidade de Coimbra, [s.l.], v. 36, p. 149-150, 1991.

VAJRĀCĀRYA, Gautamavajra. Watson collection of indian miniatures at the Elvehjem museum of art: a detailed study of selected works. Wisconsin: Chazen Museum of Art, 2002.

WEBER, Max. Ciência e política: duas vocações. São Paulo: Cultrix, 1972.

WINTERNITZ, Moriz. A history of indian literature. Delhi: Motilal Banarsidass, 1985.

WITTKOWER, Rudolf. Marvels of the East: a study in the History of Monsters. Journal of the Warburg and Courtauld Institutes, [s.l.], v. 5, p. 159-197, 1942. 